\title{
Ultrasound-guided Fine-Needle Aspiration Biopsy Is An Efficient Diagnostic Tool In Thyroid Nodules
}

\section{Ioana Armasu ${ }^{1}$, Delia Ciobanu ${ }^{2}$, Andra Istrate ${ }^{3}$, loana Vasiliu ${ }^{4}$, Lidia lonescu ${ }^{5}$, Cristina Preda ${ }^{1}$,}

Voichița Mogoş ${ }^{1}$, Carmen Vulpoi ${ }^{1}$

1 - Department of Endocrinology, 2 - Department of Morphopathology, 3 - Department of Internal Medicine, 4- Department of Phisiology, 5 - Department of General Surgery University of Medicine and Pharmacy "Grigore.T. Popa" - Iaşi, Romania

\section{Introduction}

- Thyroid nodules are commonly encountered in clinical practice:

$>$ Simple clinical examination reveals nodules $4-7 \%$ of subjects examined, the frequency increasing to $5-20 \%$ in areas of endemic goiter.

$>$ The actual frequency of thyroid nodules is significantly higher and increases with age -> autopsy studies record frequency of $40-50 \%$.

* The main diagnostic problem is the benign or malignant nature of the nodules.

* Fine--needle aspiration biopsy (FNAB) is a standard diagnostic test for evaluating thyroid nodules.

* Several studies have-showed that the use of ultrasound guidance (USFNAB) improves the diagnostic accuracy of aspiration biopsies in comparison with palpation guidance (P-FNAB) alone.

Patients and Methods
We performed a retrospective study
$>$ to compare the efficacy of US-FNAB of thyroid nodules with that of P-FNAB.
Study group:
$>$ patients referred to Endocrinology Department
$>$ for assessment of thyroid nodular disease who underwent:
- P-FNAB between 2000-2001,
- US-FNAB between 2009-2012.
In order to avoid differences due to nodules size
only palpable nodules in both groups were selected.
thyroid examinations, ultrasound imaging, and aspiration biopsies were performed by
Histopathologic and cytologic results were compared for patients who were operated.

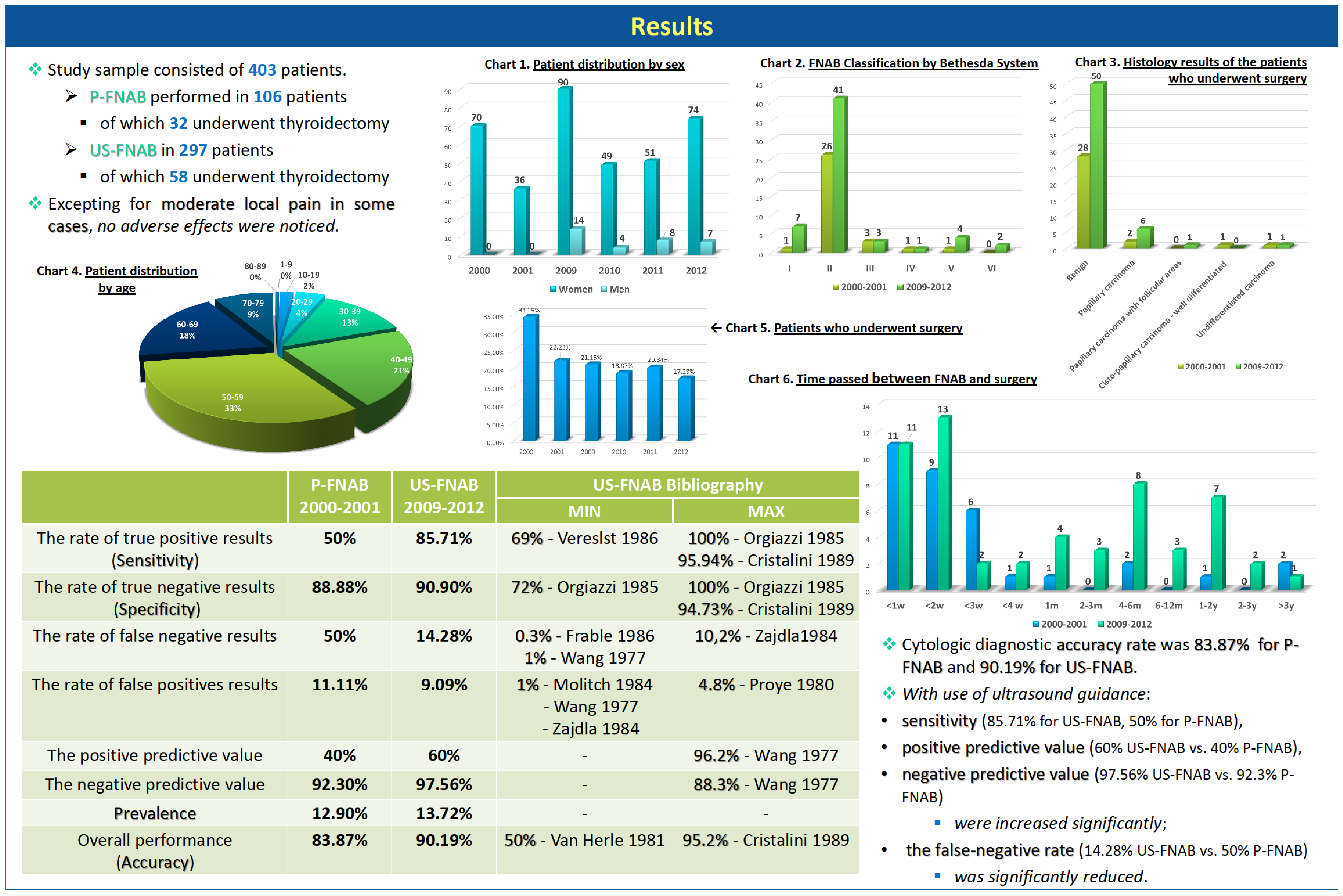

\section{Conclusions}

Fine-needle aspiration biopsy is an essential diagnostic tool in the management of thyroid nodules.

* US-FNAB improved the accuracy, sensitivity, and positive predictive value and reduced the false-negative rate of the cytologic diagnostic in comparison with P-FNAB.

- Therefore, practice guidelines should universally recommend US-FNAB in the management of thyroid nodules, permitting an accurate preoperatory diagnostic and avoiding numerous unnecessary surgical interventions.

References: Z Zbranca, E. ş.a. - Endocrinologie. Ghid de diagnostic şi tratament în bolile endocrine, Ediția a III-a, Editura Polirom, laşi, 2008, ISBN 978-973-46-1160-7; Vulpoi C. - Contribuția ecografiei în diagnosticul şi tratamentul patologiei tiroidiene, Teză de doctorat, laşi, 1998; Mogoş V.Z. - Tumorile tiroidiene, www.umfiasi.ro/Rezidenti/. Vulpoi C. - Modification of cancer profile in the last 20 years in a Romanian region International Symposium for Thyroid Cancer, Melanoma, Breast Cancer Guidelines and Palliative Care in Oncology WFSOS\&SSSO, Belgrad 2013, AACE/AME/ETA Thyroid Nodule Guidelines, Endocr Pract. 2010, 16 (Suppl 1),3; Peli M. et al. - Ultrasound guided fine-needle aspiration biopsy of thyroid nodules: Guidelines and recommendations vs clinical practice; a 12-month study of 89 patients, Journal of Ultrasound, 2012, 15:102-107; Cibas E.S. et al - The Bethesda System for Reporting Thyroid Cytopathology, American Journal of Clinical Pathology, 2009,132:658-665. 